\title{
"Não pode casar ainda/só depois que se formar": controle do corpo e formação de professoras normalistas na capital do Brasil (1920-1950)
}

\section{"She cannot marry yet/only after she graduates": body control and training of student teachers in the capital of Brazil (1920-1950)}

\author{
Fábio Souza Lima*
}

\begin{abstract}
RESUMO
O presente artigo tem por objetivo estudar o contexto histórico em que foi promulgado o Decreto n. ${ }^{\circ} 9.529$, de 28 de dezembro de 1948 na capital do Brasil. Tal normatização proibiu as discentes que viriam a se tornar professoras da rede pública de ensino municipal do Distrito Federal de se casarem e ficou vigente até o ano de 1953. Abordamos o período histórico que vai do final dos anos 1920 até o início dos anos 1950 sob uma dupla dimensão: o controle do corpo e a formação de professores. O intuito dessa investigação é colaborar para o entendimento de como a sociedade carioca em processo de modernização característico dessas décadas aceitou, formulou e incorporou normatizações que interferiam na vida privada da professora primária em formação nas duas unidades oficiais da cidade. Optamos pelo uso de periódicos da época como fontes, triangulando esse material com bibliografias acerca do conceito de gênero. Os resultados demonstraram a influência histórica e cultural da fé cristã na produção da representação das docentes, bem como o controle do seu corpo e as restrições quanto as suas perspectivas de vida. Concluímos que as pesquisas sobre o passado desse tema são tão importantes quanto as discussões realizadas hoje, pois,
\end{abstract}

*Universidade Federal do Amazonas. Manaus, Amazonas, Brasil. E-mail: fabiosouzaclima@ gmail.com - http://orcid.org/0000-0002-1855-1738 
diante do atual crescimento do conservadorismo, conhecer o passado pode nos oferecer melhores argumentos para a manutenção e criação de direitos sociais que tornarão a nossa sociedade mais justa.

Palavras-chave: História da Educação. Formação de professores. Controle do corpo. Modernização social. Normalistas.

\begin{abstract}
The purpose of this article is to study the historical context in which Decree 9.529, of December 28, 1948, was promulgated in the capital of Brazil. Such standardization prohibited female students who would become teachers in the public school system of the Federal District of getting married, and remained in force until 1953. We approach the historical period from the late 1920 s to the early 1950s under a double dimension: body control and teacher training. The aim of this investigation is to collaborate for the understanding of how the society of Rio de Janeiro, in the typical modernization process of these decades, accepted, formulated and incorporated norms that interfered in the private life of the training primary teacher in the two official units of the city. We chose to use periodicals of that time as sources, triangulating this material with bibliographies about the concept of gender. The results demonstrated the historical and cultural influence of the Christian faith in the production of the teachers' representation, as well as the control of their body and the restrictions regarding their life perspectives. We conclude that research on this topic's past is as important as the discussions held today, because, in view of the current growth of conservatism, knowing the past can offer us better arguments for maintaining and creating social rights that will make a more just society.
\end{abstract}

Keywords: History of Education. Teacher training. Body control. Social modernization. Student teachers.

\title{
Introdução
}

Em 16 de fevereiro de 1937, o então ministro da educação e saúde Gustavo Capanema deu início às discussões no Conselho Nacional de Educação para que fosse criado o primeiro Plano Nacional de Educação (PNE) do Brasil. Três meses depois, no dia 18 de maio, o projeto de PNE foi enviado ao presidente da República Getúlio Vargas, que, por sua vez, encaminhou uma cópia ao Congresso Nacional no mesmo dia. Apesar da celeridade, o projeto havia recebido muitas 
propostas, entre elas a de criação das primeiras Escolas Normais Domésticas oficiais, isto é, unidades planejadas, geridas e financiadas pelo erário público e destinadas às mulheres entre 12 e 18 anos (SCHWARTZMAN; BOMENY; COSTA, 2000; KUSCHNIR; CARNEIRO, 1999).

Ao sofrer resistências na Câmara Federal, sobretudo vindas da oposição identificada com o pensamento da Escola Nova ${ }^{1}$, a votação do projeto de PNE demorou a ser realizada. Neste ínterim, no dia 10 de novembro de 1937, os poderes representativos foram fechados e foi instaurado o Estado Novo (1937-1945), sob o comando de Getúlio Vargas. A votação do PNE de 1937 fora deixada de lado e até esquecida. Afinal, em uma ditadura com o Poder Executivo hipertrofiado, o tramite de leis não tinha qualquer importância frente aos interesses do governo autoritário de Vargas.

O modelo das Escolas Normais Domésticas, proposto originalmente pelos educadores católicos, jamais foi oficialmente adotado pela administração pública. Entretanto, o interessante a ser ressaltado é que as bases da tentativa de introdução desse modelo não consistiam simplesmente em leis, mas na influência ideológica e na atuação prática desses educadores ${ }^{2}$ apoiados em instituições atuantes como o Centro Dom Vital (1922), a revista A Ordem (1921) e a Liga Eleitoral Católica - LEC (1932) (HORTA, 2012).

Como efeito da atuação dessas instituições, um mês após a instauração do Estado Novo, o ministro Gustavo Capanema descreveu em conferência sobre a educação das mulheres:

Os poderes públicos devem ter em mira que a educação, tendo por finalidade preparar o indivíduo para a vida moral, política e econômica da nação, precisa considerar diversamente o homem e a mulher. Cumpre reconhecer que no mundo moderno um e outro são chamados à mesma quantidade de esforço pela obra comum, pois a mulher mostrou-se capaz de tarefas as mais difíceis e penosas outrora retiradas de sua participação.

1 Grupo de pensadores ligados ao modelo educacional que contestava a forma autocrática e religiosa de ensino tradicional. O movimento Escola Nova ganhou força no Brasil nas décadas de 1920 e 1930, tendo como principais nomes Fernando de Azevedo, Anísio Teixeira e Lourenço Filho. Defenderam valores como a escola pública, obrigatória, laica, unitária, coeducativa e de qualidade (XAVIER, 2002).

2 Os educadores católicos, por sua vez, pressionavam as gestões nos diferentes níveis de poder no sentido de restaurar a influência da fé cristã nas escolas públicas por meio do retorno disciplinas religiosas e a manutenção de aspectos humanísticos no ensino em detrimento de uma educação técnica. Com a Revolução de 1930, as disputas no campo educacional entre esses grupos se tornaram mais evidentes. 
A educação a ser dada aos dois há, porém, de diferir na medida em que diferem os destinos que a Providência lhes deu. Assim, se o homem deve ser preparado com têmpera de teor militar para os negócios e as lutas, a educação feminina terá outra finalidade, que é o preparo para a vida do lar. A família constituída pelo casamento indissolúvel é a base de nossa organização social e por isto colocada sob a proteção especial do Estado. Ora, é a mulher que funda e conserva a família, como é também por suas mãos que a família se destrói. Ao Estado, pois, compete, na educação que lhe ministra prepará-la conscientemente para esta grave missão (CAPANEMA, 1937 apud SCHWARTZMAN; BOMENY; COSTA, 2000).

Anos depois, o projeto de educação destinado exclusivamente para a mulher foi consubstanciado no Decreto $\mathrm{n}^{\circ}$ 4.244, de 9 de abril de 1942 (BRASIL, 1942), também chamado de Lei Orgânica do Ensino Secundário. Tal Decreto, ao tratar do tema, apresentou um título específico: "Do ensino secundário feminino". E afirmou no artigo 25 que "É recomendável que a educação secundária das mulheres se faça em estabelecimentos de ensino de exclusiva frequência feminina", ou ainda que "A orientação metodológica dos programas terá em mira a natureza da personalidade feminina e bem assim a missão da mulher dentro do lar".

Findadas a Segunda Guerra Mundial e a ditadura do Estado Novo (1945), houve uma organização ainda mais detalhada do ensino médio, desta vez tratando da formação das professoras normalistas no Decreto-Lei n ${ }^{\circ}$ 8.530/46 (BRASIL, 1946), conhecido como Lei Orgânica do Ensino Normal. Acerca da formação feminina, a lei deixava brechas que pareciam delegar a cada região do país a competência para julgar se homens e mulheres deveriam ou não realizar o curso normal. Seguindo essa liberdade de legislar, a regulamentação para o Ensino Normal no Distrito Federal, por meio do Decreto $n^{\circ} 9.529$, de 28 de dezembro de 1948 (DISTRITO FEDERAL, 1948), assegurou que tanto o Instituto de Educação quanto a Escola Normal Carmela Dutra teriam suas admissões limitadas ao sexo feminino. Além da normatização, periódicos cariocas como o Gazeta de Notícias, o Diário de Notícias, o Diário Carioca, A Noite, A Última Hora, além da revista O Cruzeiro, trataram do tema de forma a refletir as opiniões, os valores morais e os interesses públicos na imagem da professora. Os jornais refletiram uma sociedade que se urbanizava e se industrializava, mas mantinha os valores ligados ao passado rural, com baixa escolarização e muito conservadora com relação às mulheres (LUCA, 2005).

Esse processo de modernização econômica em uma sociedade de pensamento conservador está no cerne de nosso estudo, uma vez que é justamente o contexto no qual é construída a imagem das professoras normalistas. Nesse 
sentido, definimos como objetivo, entender como a sociedade carioca, enquanto capital do Brasil, aceitou, formulou e incorporou normatizações que interferiam na vida privada da professora primária em formação nas duas unidades oficiais da cidade, ao mesmo tempo em que buscava se modernizar economicamente.

Como é possível perceber, nosso procedimento teórico-metodológico aponta para o uso de periódicos de época, tais como jornais em circulação na capital do Brasil entre as décadas de 1920 e 1950. A escolha dessas fontes representa uma tentativa de aproximação com as práticas, as ideias e os valores da sociedade carioca naquele período, sendo medida no entusiasmo dos leitores pelas reportagens presentes nesses jornais. Naturalmente, tal decisão torna imprescindível algumas escolhas teóricas que passam pelas leituras dos trabalhos de Adriana Pasquini e Cézar Toledo (2014), além do estudo clássico de Tania Regina de Luca (2005). A análise de periódicos, como metodologia, necessita inicialmente do conhecimento das nossas fontes, seus interesses, suas ideologias e grupos políticos envolvidos, pontos que abordamos na medida em que utilizamos os periódicos no decorrer deste artigo.

Nesse sentido, foi também necessário, assim como defendem os autores citados, a realização das triangulações de fontes, relacionando os noticiários às bibliografias específicas que nos ajudaram a problematizar o nosso estudo. Assim, acreditamos que a melhor aproximação com o tema pode ser realizada com a escolha da categoria de gênero, encontrado nos trabalhos de Johan Scott (1992) e Guacira Lopes Louro $(2003,2018)$. Enquanto Scott realiza uma conceituação de gênero presente em todo o nosso texto, Louro traz aspectos da atuação das professoras brasileiras em parte do recorte cronológico que estabelecemos.

\section{Quem melhor para mudar a sociedade?}

As reformas educacionais realizadas no final dos anos 1920 pelo então Diretor Geral de Instrução Pública do Distrito Federal, Fernando de Azevedo, entre muitas outras coisas, acrescentaram um ciclo profissional à formação humanística do curso normal. A mudança trouxe um caráter mais técnico à formação de professores, até então de tradição fortemente católica e humanística. Ligada a essa reforma, um novo processo de contratação de professores passava a ser realizado por concurso, o que representou um marco importante para a profissionalização da carreira docente.

Desde então, os postos de docentes deixaram de ser ocupados por intelectuais de reconhecimento na comarca onde atuavam, para se tornarem 
cargos destinados a especialistas com formação adequada dada pelos cursos normais para atuar no magistério (SILVA; VIDAL; ABDALA, 2020; XAVIER; FREIRE, 2002). Se, por um lado, a cobrança de um diploma específico para lecionar nas escolas da rede municipal oficial dos anos 1930 se tornava uma prática de modernização e profissionalização do professor, por outro lado, a influência dos duzentos anos passados de educação jesuítica, por meio dos valores morais, dos costumes e das práticas, igualmente ainda se fazia presente.

Palavras como messias, missionário e missão, ligadas irreversivelmente ao passado de Colônia e Império, se mostraram expressões impossíveis de serem deixadas de lado mesmo depois de quatro décadas de República. Essas três palavras têm em sua raiz a ideia de que uma responsabilidade fora delegada a alguém, de quem se espera nada menos do que o cumprimento de sua tarefa. Além disso, ao pensarmos na proximidade entre profeta e professor, ambos com raízes na concepção de que esses personagens são aqueles que estão à vista de dizer algo a alguém, fica ainda mais difícil separar o dom de um pastor e a profissão de um educador diante de suas atividades sociais em um período em que a República brasileira era ainda muito jovem.

Como forte exemplo dessas relações de permanência na imagem do professorado brasileiro - e também em alusão às disputas entre educadores católicos e escolanovistas, citamos o estabelecimento do Dia do Mestre. As comemorações sobre o dia do professor como 15 de outubro remontam ao tempo do Brasil Império, mais especificamente ao ano de 1827. Originalmente, tal data faz referência à primeira lei sobre o ensino primário, em que ainda era tarefa do professor lecionar sob os "principios de moral christã e da doutrina da religião catholica e apostolica romana" (sic) (BRASIL, 1827). Apesar disso, será no contexto de um Estado laico que a comemoração verdadeiramente se estabelece.

A inauguração do prédio da Escola Normal do Distrito Federal (1930), onde funcionou a partir de 1932 o Instituto de Educação, por influência direta dos educadores da escola nova, fomentou o crescimento do prestígio da profissão de professor. Mas, em 1933, foi a Associação dos Professores Católicos do Distrito Federal (APC-DF) que festejou pela primeira vez o Dia do Primeiro Mestre, na data de 15 de outubro. Nos anos seguintes, essa associação lançou um apelo para que todos no país externassem sua gratidão com flores aos professores. Assim sendo, tendo a sociedade respondido ao chamado de homenagem aos docentes, o grupo também elaborou uma comissão que buscou junto aos órgãos públicos a oficialização da data comemorativa (VICENTINI, 2007).

No Distrito Federal, em 1951, a campanha se desenvolveu ainda mais a partir da iniciativa do jornal Última Hora, apoiador contumaz do governo Getúlio Vargas. O periódico, a fim de realizar um concurso visando eleger o patrono do professorado carioca, atendia na verdade as bases que sustentaram o governo 
pelos anos seguintes (PASQUINI; TOLEDO, 2014). Em meio a muitas figuras do concurso, entre elas personalidades republicanas e não religiosas, sobressaiu o nome do Padre José de Anchieta, missionário evangelizador do século XVI, considerado como aquele que introduziu o catolicismo no Brasil.

José de Anchieta foi eleito com 26.641 votos dos 86.561 apurados. A eleição do jesuíta pode ser considerada um indicativo da influência da Igreja Católica junto aos participantes do concurso, incluindo as alunas das duas escolas normais oficiais do Distrito Federal [Instituto de Educação e a Escola Normal Carmela Dutra], das quais se esperava o voto em Benjamin Constant. A simbologia de sua figura remetia para uma concepção sacerdotal da docência em que sacrifício, abnegação e dedicação se associavam na descrição de um mestre exemplar (VICENTINI; LUGLI, 2009, p. 169).

Ao mesmo tempo em que a sociedade brasileira ainda se alicerçava em referenciais dos séculos XVI a XIX, as modernizações políticas, econômicas e culturais a partir dos anos 1930 interferiram diretamente no ser social do povo brasileiro. A nova proposta de país mudava o eixo econômico do agropecuário para o industrial e o eixo político do rural para o urbano, podendo ser resumida nas palavras de Getúlio Vargas, descritas na Carta de São Lourenço. Vargas apontou que sua política econômica tinha como pontos básicos a criação de uma indústria de base, especificamente da siderurgia, bem como a nacionalização das fontes de energia, dos bancos estrangeiros, a diversificação das exportações e um plano geral de integração e expansão dos transportes, entre outros pontos que ilustravam os novos caminhos do país. Para tanto, era necessário que o ser social brasileiro fosse transformado (CORSI, 2002).

Diante desse desafio, o professorado do Distrito Federal fora convocado para a missão de converter o povo brasileiro, visto por frações de suas elites como incivilizado, doente e indolente (CARVALHO, 2006; OSTOS, 2012).

Embora muitos políticos e intelectuais concordassem que não possuíamos ainda uma nação e um povo, muitos também consideravam que um dos caminhos seguros para atingir tal meta era o dos bancos escolares, a começar pela instrução primária. Foi essa certeza que tornou a figura do professor primário uma chave da escola republicana. Como ela era, por excelência, um local de aprendizado não só de conhecimentos, mas de valores cívicos e morais necessários à regeneração (lenta, é verdade) de toda a sociedade, o professor encarnava esse objetivo transformador. Ele precisava ganhar prestígio e reconhecimento social para que então 
pudesse ter autoridade em sua missão. Justamente por isso, o professor, além de possuir saber técnico para o exercício do magistério, tinha que ser um modelo de virtude. [...] as professoras primárias eram definidas como verdadeiras "construtoras da nação", e a profissional modelo era aquela formada nas escolas normais (GOMES, 2002, p. 404-405).

Ajudou nesse processo a crescente ideia de que a escola era uma espécie de passagem do lar ao mundo do trabalho, sendo que não havia ninguém melhor do que a mulher para preparar a criança para essa transição (SCOTT, 1992). Com isso, termos como autoridade moral, cuidado infantil, maternagem, extensão da maternidade, mãe espiritual, minuciosidade, paciência, afetividade, doação e por natureza, foram diversas vezes aplicados em jornais, revistas, discursos políticos e nas falas do senso comum (CARVALHO, 2005; LOURO, 2018).

Imbuída de qualidades de virtude e civismo, a professora se tornou a personagem central para sustentar esse período de transformação social, política, econômica e cultural. Por isso, na composição dos hinos das unidades de formação de professores do DF, não faltaram referências ao nacionalismo, ao desenvolvimento da nação e à missão de levar o conhecimento à população.

Hino do Instituto de Educação (1947)

Instituto fanal cuja história/ tradições e lauréis vem lembrar!/ Óh! luzeiro sem par, tua glória/ Vimos todos de pé celebrar!/ Teu clarão nossas almas inflama/ Faz bem presto convictos sentir/Que o destino da pátria reclama/ Nossa oferta no altar do porvir! [...] Afirmamos no ardor do civismo/ Nossas vidas ao bem consagrar/ Santa Cruz jamais viu patriotismo/Tão grandioso o seu nome exaltar!/ Prometemos formar paladinos/ Conduzilos em luz e labor/ Corações que proclamem os hinos/ Da justiça, da paz e do amor!!/ Salve, glória te rendemos/ Com orgulho juvenil/ Passo firme caminhemos/ À vanguarda do Brasil! (CAMPOS; BRANDÃO, 1949 apud TONÁCIO, 2011, p. 12).

Hino da Escola Normal Carmela Dutra (1949)

Pela pátria, família e escola/ Trabalhemos com fé, com valor/ E uma vida de luz e beleza/ Seja nosso fanal, nosso amor/ O Brasil nosso esforço reclama/ Somos força real do país/ Estudemos e a pátria façamos/ Poderosa, brilhante e feliz /As virtudes do lar, dom celeste/ Enobreçam o nosso pendor/ E a Escola Normal Carmela Dutra/ Exaltemos vibrando de amor $^{3}$ (DISTRITO FEDERAL, 1949). 
Com interesses em ajustar o corpo e a vida da professora à imagem presente no novo projeto educativo de nação, as escolas normais do DF passaram a exigir das candidatas um perfil físico absolutamente diferente da visão que os intelectuais brasileiros tinham do próprio povo, muitas vezes ligados a personagens como Macunaíma, de Mário de Andrade e Jeca Tatu, de Monteiro Lobato (LIMA, 2016; OSTOS, 2012). Como base, foi usada a Lei Orgânica do Ensino Normal, que preconizava em seus artigos 20 e 21 que para admissão ao curso normal o candidato deveria, além de ser habilitado nos exames, ser brasileiro e demonstrar sanidade mental, apresentar-se também sem defeitos físicos ou distúrbios funcionais, ter bom comportamento social e até 25 anos de idade (BRASIL, 1946).

Com uma população de cerca de $80 \%$ de analfabetos, subnutrida e que ainda discutia fortemente nos anos 1930 o papel da educação para dirimir os problemas de higiene no país, os editais de seleção para o curso de formação de professores se tornavam restritos a uma pequena parcela da população (CARVALHO, 1998; VIDAL; FARIA FILHO, 2002). No Distrito Federal, a restrição era ainda maior, pois, por decisão da prefeitura, estava limitada às mulheres (BRASIL, 1946). Para além do que já fora pedido na Lei Orgânica do Ensino Normal, o edital abaixo ilustra perfeitamente a ideia de modelo no qual a professora deveria caber, caso quisesse o cargo de docente na rede pública da capital do Brasil.

Não serão aceitos à matrícula na Escola Normal Carmela Dutra: a) Apresentarem condições de higiene individual e asseio corporal deficientes; b) Apresentarem estado de nutrição que se afaste exageradamente da normalidade [...] podendo ser levado em consideração o índice de Kaup [...]; c) Apresentarem acuidade visual inferior a $2 / 3$ da normal para longe [...] por causas não corrigíveis e progressivas; ou enquanto forem portadores de afecções não cicatrizadas ou progressivas; d) Apresentarem acuidade auditiva anormal ou afecção evolutiva em qualquer dos ouvidos; e) Apresentarem lesões ou perturbações naso-faríngeas, salvo quando derivarem de causas removíveis; f) Apresentarem amídalas em condições de infecções [...]; g) Apresentarem afecções crônicas da laringe ou anormalidade de fonação [...]; h) Apresentarem afecções do sistema nervoso; i) Apresentarem afecções do sistema circulatório; j) Sofrerem de doenças infecciosas transmissíveis; 1) Sofrerem de doenças repugnantes; $\mathrm{m}$ ) Sofrerem de doenças endócrinas graves; $n$ ) Sofrerem de defeitos físicos ou chocantes para o meio infantil; o) Sofrerem de distúrbios neuro-psíquicos; p) Apresentarerem cavidades dentárias (cáries, raízes [...]); q) Apresentarem anomalias de posição dos dentes [...]; r) Apresentarem falta definitiva de $1 / 5$ da dentadura correspondente a sua idade; s) Apresentarem más condições de higiene bucal; [...] desde que apresentem estatura superior a 1,50m (sic) (DISTRITO FEDERAL, 1946). 


\section{“Não pode casar ainda/ só depois que se formar": 1948 a 1953}

Se o edital de 1946 parece restritivo, precisamos considerar que cerca de vinte anos antes, foi ainda proposto tornar o celibato uma prática obrigatória para a atividade docente. Logo abaixo, duas opiniões datadas de 1927 de professores sobre o tema, encontradas na pesquisa das historiadoras Diana Vidal e Marília Pinto de Carvalho (2001). Na primeira, a diretora da Escola Profissional Feminina Rivadávia Corrêa, a professora Beneventura Ribeiro, descreve sua própria rotina, trazendo os elementos da imagem da professora que já destacamos anteriormente.

Sou francamente favorável ao celibato das professoras, por julgá-lo uma necessidade para o ensino. Não digo isso porque sou celibatária. Digo porque essa é minha convicção. Acho que a professora quando se casa deve isolar-se do ensino. Se enviuvar ou se a assaltarem dificuldades prementes estão poderá voltar a exercer sua atividade numa escola. [...] Professora é uma vocação, é uma profissão de renúncia. Professora não deve ser aquela que precisa ganhar a vida, mas aquela que se julgue capaz de o ser e com coragem suporte todos os sacrifícios (VIDAL; CARVALHO, 2001, p. 217).

Beneventura Ribeiro foi diretora da unidade feminina entre os anos de 1913 a 1961, representando o DF em eventos como a Conferência pelo Progresso Feminino, organizada na cidade pela Federação Brasileira pelo Progresso Feminino (BONATO, 2008). Sua fala não apenas ressalta os elementos que remontam à ideia de missão do magistério, mas também de renúncia à vida de casal e aos filhos, tal como uma missionária deve fazer. A outra fala é realizada pelo professor Luiz Palmeira, que, apesar de defender o trabalho da mulher como professora, o faz com base em uma pseudociência que no século XIX havia inventado a doença paroxismo histérico ${ }^{4}$.

4 No século XIX, as mulheres superavam os homens em número nos asilos europeus. Isso facilitou o entendimento popular de que a mulher era mais propensa a distúrbios psiquiátricos do que o homem. Sintomas como dores de cabeça, irritabilidade, insônia, choro sem explicação e ansiedade eram diagnosticados como paroxismo histérico, oriundo de perturbações do útero. $\mathrm{O}$ tratamento indicado era a masturbação a ser realizada em consultórios (SAUL, 2008). 
E, depois, o que se nota numa escola infantil é que a professora casada é mais carinhosa, mais paciente do que a solteira. Esta, em via de regra, quando alcança uma certa idade, quando certos fenômenos do seu sexualismo atingem determinados pontos, o seu psiquismo é vitimado por um desequilíbrio nervoso (VIDAL; CARVALHO, 2001, p. 217).

A proposta de imposição do celibato às professoras não prosperou, mas também não se tornou um tema esquecido nas décadas seguintes. $\mathrm{Na}$ segunda metade dos anos 1940, com a indústria de base recém-instalada e uma nova realidade de urbanização da sociedade brasileira em andamento, o conservadorismo brasileiro retomava as discussões sobre o papel da mulher.

[...] Não é preciso que façamos malabarismos de raciocínio para admitir que, se por um lado é ideal a permanência da mulher no lar, por outro lado devemos considerar a realidade do mundo contemporâneo, em que a mulher é obrigada a trabalhar fora de casa colaborando com seu consorte no sustento da família (A SITUAÇÃO..., 1949, p. 16) - [Correio da Manhã].

Nas eleições presidenciais de 1945, entre o brigadeiro Eduardo Gomes, cujas admiradoras criaram o slogan "Vote no Brigadeiro. Além de bonito, é solteiro", e o General Eurico Gaspar Dutra, que levava a bandeira da continuidade do governo Vargas, o povo brasileiro escolheu a segunda opção para o mandato de 1946 a 1951. Dutra havia sido ministro da guerra de Getúlio Vargas durante a segunda guerra mundial e teve como principal cabo eleitoral na campanha a fervorosa católica D. Carmela Dutra, sua esposa.

Chamada socialmente de Santinha, D. Carmela Dutra havia sido aluna da Escola Normal do Distrito Federal e professora primária da rede pública do DF. Sofreu uma intensa investigação realizada em 1942 na qual o FBI estadunidense apontou que ela estaria convertendo os mais altos círculos sociais brasileiros a entrar na guerra ao lado dos nazistas, o que efetivamente não ocorreu, pois naquele ano Vargas optou por entrar na guerra ao lado dos EUA. Como primeira dama, D. Santinha maldisse as enfermeiras que decidiram ir para a Europa para cuidar dos soldados na guerra, comparando-as com prostitutas que buscavam maridos. Também ajudou a eleger políticos no Distrito Federal e teve atribuída a sua influência sobre o marido a proibição dos jogos de azar em $1946^{5}$ e o fechamento do Partido Comunista do Brasil em 1947 (LIMA, 2016). Faleceu 
em 1947, sendo homenageada pelo jornal carioca A Noite: "O exercício do ciclo do magistério a tornou credora da admiração de uma boa parcela de brasileiros, que ela soube educar, consonante os princípios de sua formação, sempre austera na salvaguarda da moral e dos bons costumes. [...] um espelho das virtudes da mulher brasileira" (Sic) (ENLUTADA..., 1947, p. 2) [A Noite].

Nesse curto período em que D. Santinha se tornou a primeira dama do Brasil, o militar Ângelo Mendes de Morais foi promovido a General de Divisão em agosto de 1946 e foi nomeado prefeito do Distrito Federal um ano depois pelo presidente Dutra. Morais providenciou em sua gestão a nomeação do médico pessoal de D. Carmela Dutra para a secretaria de educação e saúde, que, por sua vez, criou a segunda unidade de formação de professores do DF. Ao criar a unidade, o médico Fioravanti Di Piero a nomeou como Escola Normal Carmela Dutra $^{6}$, em homenagem a quem verdadeiramente lhe dera o cargo. A gestão de Morais ainda nos dias atuais é lembrada pela construção do Estádio Jornalista Mario Filho (Maracanã - 1950), mas não foi só isso. Outra ação de sua gestão foi a promulgação do Decreto n. ${ }^{\circ}$ 9.529/1948 (DISTRITO FEDERAL, 1948), que proibiu a professora em formação de se casar (LIMA, 2017).

Art. 49. São condições gerais para a matrícula em qualquer série que o matriculado seja solteiro, de idoneidade moral e que não sofra de doença transmissível ou de defeito que torna desaconselhável o seu convívio com outros alunos ou que o incapacite para o exercício do magistério. Parágrafo Único. As alunas de ensino normal da Prefeitura do Distrito Federal que contraírem matrimônio, durante o curso, terão suas matrículas automaticamente canceladas (DISTRITO FEDERAL, 1948, p. 9.262-9.264).

Os jornais do DF exploraram as diferenças de opiniões da sociedade na época. Os posicionamentos variaram entre o apoio à medida da prefeitura e a desconfiança sobre a necessidade de legislar sobre o corpo das futuras professoras (LUCA, 2005; PASQUINI; TOLEDO, 2014). É interessante ressaltar que essas jovens iniciavam a formação no curso normal a partir dos 14 anos de idade, sendo permitido o ingresso com idade limite de 25 anos de idade. Considerando ainda que, ao terminar o curso, as docentes se tornavam automaticamente servidoras

6 A Escola Normal Carmela Dutra (ENCD) permaneceu submetida administrativamente ao Instituto de Educação (IE) entre os anos de 1946 a 1953. Por essa razão, em vários documentos e notícias de periódicos, aparece apenas a referência ao IE, como se a ENCD fosse apenas um posto avançado no interior carioca. 
da rede municipal de ensino, a proibição do casamento enquanto alunas tinha agora o argumento de proteção ao investimento público.

É razoável essa proibição, tendo-se em vista que a aluna do Instituto de Educação só poderá realmente, se devotar ao estudo, se de fato fôr solteira, sem os ônus do estado de casada, que são muitos e que podem afetar totalmente o aproveitamento da jovem que vai ensinar. Psicologicamente é uma medida razoável, de higiene didática, se se pode dizer tal coisa. Todo o mundo concordará que é natural que a Municipalidade exija que as alunas do Instituto permaneçam solteiras em todos os anos do curso, e só se casem depois de formadas. [...] não haverá dificuldade para ninguém, porque as próprias candidatas ao magistério, enquanto estudam só acreditam no "flirt" e no namoro. E fazem muito bem. Assim estão ajudando a administração pública (NAMORO..., 1949, p. 3) - [Gazeta de Notícias].

Entre um diploma e um marido - o coração não balança, a escolha está feita, que vá às urtigas o diploma. Fica justo, assim, que tenham os diplomas as que não puderam conquistar os maridos. O perigo, no caso, não será educativo, nem social: será estético. Pode acontecer que uma seleção natural venha a constituir de alunas menos belas e graciosas a maioria do Instituto de Educação... (DIPLOMA..., 1949, p. 4) - [Correio da Manhã].

Ao passo em que defendia a nova regra como "justa e razoável”, a reportagem do Gazeta de Notícias apontava a inconstitucionalidade diante da Carta Magna de 1946. O Correio da Manhã ainda acrescentou que uma classe seria prejudicada, a classe dos "Maridos de Professoras". O Diário Carioca, por sua vez, foi além e publicou matéria em tom jocoso:

Contra o "Marido de Professora"...

Pode ser também que o organizador da lei interna do Instituto de Educação tenha tido o propósito de acabar com essa coisa de "marido da professora", que constitui uma das nossas mais antigas tradições, ou melhor, instituições.

Quem aspirar ao título, que é uma espécie de "príncipe consorte" que espere a conclusão do curso. Mas como as noivas são apressadas, com receio de que o peixe coma a isca e cuspa no anzol praticamente acontece que todas pegam o anel de casada e mandam às favas o diploma. $\mathrm{E}$, assim, vai mesmo acabando a alta função de "marido de professora" (sic) (CONTRA..., 1949, p. 4) - [Diário Carioca]. 
Por outro lado, na mesma data, os escritores e jornalistas Rubem Braga (1949, p. 3) e Raimundo Magalhães Júnior (1949, p. 1) (que mais tarde se tornou membro da Academia Brasileira de Letras - 1956), descreveram em suas colunas no Jornal Diário de Notícias a aflição das futuras professoras da rede pública municipal de ensino do DF. Embora se posicionassem contrariamente à medida do prefeito, nas palavras dos dois autores ficam evidentes os traços de moralidade em que a regra foi criada, respectivamente:

Foi um santo que disse isto: "antes casar, que arder". As alunas do Instituto de Educação estão proibidas de casar pelo novo regulamento aprovado pelo general Mendes de Morais As que forem acometidas, durante o curso, do mal do amor (que não é doença rara no coração das normalistas) e acaso forem pedidas em casamento, ficarão em drama.

O Curso é longo, o amor é uma urgência d'alma, a espera uma agonia, o futuro uma incerteza. Os rapazes do Rio de Janeiro são, em geral, muito cavalheirescos; mas vamos convir em que há alguns malandros que darão preferência a namoradas normalistas, em vista da proibição. Saberão, no caso da moça se dispor a deixar o curso, alegar escrúpulos finos: apesar da paixão que o abrasa, êle, o biltre, não se julga com direito de interromper a carreira da moça.

A proibição aumentará talvez as aflições do amor, que já é, de seu natural, uma aflição que dá na pessoa. Não entendo de pedagogia, e não conheço os altos motivos que inspiraram esse artigo 49 do Regulamento. Também não entendo - ai de mim! - de coração de normalistas, e não sei se para eles o artigo 49 será um sinal de sossego ou um motivo de inquietação. Sei apenas que eu por mim não ousaria assinar tal regulamento; pois é uma coisa sempre por demais delicada fazer regulamentos para o coração dos outros. Já há tanta coisa proibida, e tanta moça sem casar! (sic) (BRAGA, 1949, p. 3) - [Diário de Notícias].

Em primeiro lugar, a Municipalidade nada tem que ver com o estado civil das normalistas. O Instituto de Educação não é uma escola de solteironas, uma câmara de esterilização, nem o casamento de uma moça em idade núbil pode contrariar os interesses do Município ou do ensino. [...] País tropical, em que a puberdade vem cedo e a média de vida é curta, é bem fácil de se compreender o açoitamento de algumas moças em assegurar a posse de um marido. E é bem mais fácil compreender-se isso do que a ferocidade das autoridades do ensino, lançando-se contra as normalistas que casam... Como se casar fosse algum crime! [...] (sic) (MAGALHÃES JÚNIOR, 1949, p. 1) - [Diário de Notícias]. 
A revista $\mathrm{O}$ Cruzeiro, em reportagem intitulada As professoras do futuroVestida de Azul e Branco, entrevistou alunas do IE, revoltadas com a proibição do casamento. Entre muitas poses em fotos que inclusive mostravam as jovens na piscina, a matéria de quase dez páginas de José Leal e de José Medeiros $(1949$, p. 24), apontou que: "o resultado de toda a celeuma provocada pelo caso foi o aparecimento de um samba que está em grande voga no momento aqui no Rio. Tem uma bonita letra, música fácil e chama-se 'Normalista"'. A música "Normalista" (1949a) foi gravada na voz de Nelson Gonçalves naquele mesmo ano, aproveitando as discussões na sociedade carioca sobre a proibição do casamento para as normalistas. A revista ainda realizou outra reportagem:

\section{"NORMALISTA" - UM GRANDE SUCESSO}

Colocada há dois meses no primeiro lugar absoluto do "hit-parade", de David Nasser e Benedito Lacerda, está na frente em vários setores. Eis a classificação do sucesso do ano:

Venda de discos $-1 .^{\circ}$ Lugar - "Normalista"

Orquestrações - $1 .^{\circ}$ Lugar - "Normalista"

Venda de música papel - $10^{\circ}$ Lugar - "Normalista"

Execução em "boites" - 2. . Lugar - "Normalista"

Execução em rádio - 1. ${ }^{\circ}$ Lugar - "Normalista"

Execução em bailes - $1 .{ }^{\circ}$ Lugar - "Normalista"

"Wurl Litzer" (vitrolas de cafés) - 1. ${ }^{\circ}$ Lugar - "Normalista"

O samba "Normalista" bateu êste ano recordes de vendagem na RCA, Victor nos editores irmãos Vitale. A título de curiosidade reproduzimos os versos que estão sendo cantados em todo o Brasil:

Vestida de azul e branco/ Trazendo um sorriso franco/ No rostinho encantador/Minha linda normalista/ Rapidamente conquista/ Meu coração sem amor/Eu que trazia fechado/ Dentro do peito guardado/ Meu coração sofredor/ Estou bastante inclinado/ A entregá-lo ao cuidado/ Daquele brotinho em flor/ Mas, a normalista linda/ Não pode casar ainda/ Só depois que se formar/ Eu estou apaixonado/O pai da moça é zangado/ E o remédio é esperar (sic) (NORMALISTA..., 1949b, p. 40) - [O Cruzeiro].

Outra música que fez sucesso foi "Professora", também de Benedito Lacerda, mas agora em parceria com Jorge Faraj e Sílvio Caldas. Originalmente de 1938, foi regravada em 1949 por Alcides Gerard, na esteira da fama de Nelson Gonçalves. 
E no trem das professoras/ Em que outras vão, sedutoras/ Eu não vejo mais ninguém/ Essa operária divina/ Que lá no subúrbio ensina/ As criancinhas a ler/ Naturalmente condena/ Na sua vida serena/ O meu modo de viver/ Condena por que não sabe/ Que toda culpa lhe cabe/ De eu viver ao Deus dará/ Menino querendo ser/ Para com ela aprender/ Novamente o be-a-bá (PROFESSORA, 1949).

Concorreu para essa fetichização das professoras normalistas a criação do uniforme que se tornou famoso por meio de livros, filmes e séries de televisão. Embora o afamado uniforme azul e branco tenha sido estabelecido em 1946, sua origem remonta a 1914, época em que a Escola Normal do Distrito Federal (ENDF, futura IE - 1932) estava instalada em uma região repleta de prostíbulos, no Estácio, centro do Rio de Janeiro. Nesse ano, o Coronel Leite Ribeiro, que havia sido interventor federal na cidade em 1902, propôs a criação do uniforme sob três motivações: indistinção entre alunas ricas e pobres; criação de um espírito de classe; diferenciação das "não poucas criaturas de moralidade duvidosa" (LIMA, 2018, p. 171).

Dentro desse quadro, havia internamente um movimento para superar a lei que legislava sobre o corpo daquelas jovens. As palavras da vereadora do DF Ligia Lessa Bastos (União Democrática Nacional - UDN), ex-aluna do IE, demonstravam a realidade das alunas na época e também traziam a dimensão de que o sucesso na vida da mulher era pensado em função do casamento e da criação dos filhos.

A tragédia começa quando vão ter a criança”, Declara Lígia Lessa Bastos - Grande Incidência das Solteironas - "Fui Vítima da Proibição Absurda". As alunas do Instituto de Educação - declarou a vereadora Lygia Bastos a nossa reportagem - vinham se casando às escondidas, para fugirem a proibição legal. Quando chegava a época de terem crianças, eram descobertas e, então, o rigorismo dos dispositivos desumanos se faziam sentir e elas eram expulsas. Aconteceu isso várias vezes [...] Ligia disse, ainda, que a proibição vem aumentando o número de solteironas. As moças, para não infringirem a lei, retardam o casamento, perdendo, quase sempre, as melhores oportunidades, inclusive a maior de todas, a da idade mais própria. Quando podem se casar, encontram dificuldades às vezes invencíveis, e ficam solteiras. [...] O que aconteceu comigo acontece com outras. De forma que proibir, por lei, que uma moça se case na época em que mais sonha com o casamento, é um crime (AS ALUNAS..., 1952, capa) - [Diário Carioca]. 
À parte da situação da solteirona, descrita pela vereadora udenista, correspondia chamar a mulher de: "desgraciosa, aquela que não conseguiu casar, a solteirona retraída e desconfiada. Afinal, o casamento e a maternidade constituíam o destino natural e desejado para todas as mulheres" (LOURO, 2003 , p. 80). Ligia Bastos apresentou seu projeto para acabar com a proibição em 1952, mas ele recebeu parecer favorável apenas em 1953, mesmo ano em que foi votado. Antes, porém, o Decreto foi amplamente discutido nos jornais, cativando a população a participar do debate sobre o corpo e a vida privada de mulheres que poderiam ter entrado no curso normal com até 25 anos e estarem próximas dos seus 30 anos no período de formatura.

"Há cinco anos venho esperando uma boa oportunidade para realizar o meu maior ideal: casar e continuar os estudos" - declarou a senhorita Tereza Martins, ao D.C., a propósito do projeto da vereadora Lígia Maria Lessa Bastos que concede às futuras professoras o direito de casar. "Eu e meu noivo estamos confiantes na vitória deste projeto - acrescentou o "broto" (A NORMALISTA..., 1952, p. 12) - [Diário Carioca].

CASADAS CLANDESTINAS - Segundo pudemos verificar, entre as alunas do nosso Instituto de Educação, a grande maioria deseja que o projeto seja aceito pela Câmara [...]. Também nos foi confessado que existem entre elas várias alunas que são casadas e que precisam sempre tirar a aliança quando entram no Instituto para as alunas. É principalmente para essas que o DIÁRIO DA NOITE fez a campanha de "O direito de casar" (sic) (DEFENDEM..., 1953, p. 4) - [Diário da Noite].

Raimundo Magalhães Júnior (1953), em matéria que trazia na contracapa do Diário de Notícias um título discutível, "Mulher não casa quando quer, mas quando é querida", talvez tivesse a intenção de estimular a liberdade feminina:

Está sendo discutida, mais uma vez, a questão do casamento das normalistas. O ex-prefeito da cidade, general Ângelo Mendes de Morais, resolveu proibir, em portaria, que as normalistas se casassem. Uma vez casadas, eram excluídas do Instituto de Educação e da Escola [Normal] Carmela Dutra. Excluídas automaticamente, por simples efeito do matrimônio, sem levar em conta a frequência às aulas, o aproveitamento nos estudos, o desempenho dos deveres escolares. Poderiam ser as melhores alunas do mundo, as mais compenetradas, as mais estudiosas 
e diligentes, mas não poderia de maneira alguma continuar no convívio de suas colegas. Era como se ficassem moralmente incompatibilizadas, como se tivessem contraído uma moléstia infecto-contagiosa, como se sua presença nas aulas ameaçasse de desagregação o próprio ensino. [...] Os cursos prolongados e difíceis não podem constituir obstáculo ao casamento, numa idade em que o matrimônio deve ser encarado como uma solução natural e não afastado como coisa indesejável, nociva. [...] O Instituto de Educação e a Escola [Normal] Carmela Dutra não têm como finalidade a preparação de solteironas, nem a Prefeitura pode impor o celibato às professoras públicas. Mesmo que tentasse fazê-lo, tal medida pecaria pelo absurdo. E esbarraria na Constituição da República (sic) (MAGALHÃES JÚNIOR, 1953, p. 3) - [Diário de Notícias]

Em meio às diferentes opiniões de educadores e parlamentares, o posicionamento de religiosos que antes relacionavam a docência ao celibato sacerdotal, se alinhou a argumentação na Câmara dos Vereadores do DF de que mulher deveria seguir o que seria "o conselho de Deus", isto é, "crescei e multiplicai-vos" (ANTI-CRISTÃ..., 1953, p. 3) - [Diário da Noite]. Seguindo uma verdadeira brecha no pensamento conservador da época, o vereador do Distrito Federal Rubem Cardoso (Partido Social Progressista - PSP) ainda ressaltou no fim de sua fala, pouco antes da votação da matéria:

- Se consideramos a questão sob o aspecto familiar, acho até vantajoso para o exercício do magistério o fato de ser a professora casada, porque com a constituição da família, se desenvolverá paralelamente, o amor à criança tão necessário aos membros do magistério primário da municipalidade. Ora, se a normalista constitui família, estará desenvolvendo "a priori” um sentimento que mais tarde lhe será necessário para o bom desempenho de sua função (ANTI-CRISTÃ..., 1953, p. 3) - [Diário da Noite].

Apesar das mudanças sociais e econômicas presentes nesses anos, ainda era possível sentir o veio de uma moral advinda de séculos de colonização nas matérias de jornais da cidade. Dessa maneira, com um argumento apenas envernizado pela modernização, a norma de proibição do casamento de 1948 foi reinterpretada como uma lei anticristã. $\mathrm{O}$ entendimento agora era que a norma impedia um dos mais poderosos sacramentos da igreja, o casamento. Os jornais dos anos 1950 reverberaram esse posicionamento, mostrando que a modernização política e econômica havia começado a afetar culturalmente a sociedade brasileira (LUCA, 2005). 
O projeto de Ligia Bastos foi aprovado na Câmara por 23 votos a 17, mas o prefeito Dulcídio Cardoso (Partido Trabalhista Brasileiro - PTB) se antecipou e invalidou a norma que impedia o casamento das normalistas. O Decreto n. $^{\circ}$ 9.529, de 28 de dezembro de 1948, fora assim revogado no dia 17 de julho de 1953 pelo Decreto n. ${ }^{\circ} 12.158$ (CONTRAIR..., 1959, p. 6) - [Diário da Noite].

Os claros sinais de modernização cultural da sociedade carioca se tornaram ainda mais fortes na década seguinte, com os movimentos feministas, a criação da minissaia, da pílula anticoncepcional e das campanhas pró-aborto. Contudo, esses avanços extrapolam nosso recorte histórico. Então, por ora, conforme havia antecipado o jornal Diário Carioca em julho de 1953:

Estão, pois, de parabéns, as alunas do Instituto de Educação e da Escola [Normal] Carmela Dutra. Podem começar a preparar o enxoval e marcar o dia do casamento. Que sejam felizes! (NORMALISTAS, 1953, p. 12)

- [Diário Carioca].

\section{Considerações finais}

A música de Benedito Lacerda sobre a espera da formatura da "Normalista" (1949a) deixou de ser atual no que dizia respeito à Lei, pois a proibição do casamento foi revogada em 1953. No entanto, as representações produzidas sobre as professoras entre as décadas de 1920 e 1950, permanecem até os dias de hoje para a maior parte da população.

Ainda reverbera pela estrutura da sociedade brasileira a noção de que a professora e o professor são missionários. Uma representação que tem servido como principal elemento de discurso de alguns gestores públicos e muitos gestores privados, que insistem em não pagar salários dignos aos docentes. Afinal, por que pagariam um bom salário a um docente, se um missionário tem como base a abnegação e a vida simples? Ao colocar essa pergunta, diante do que já escrevemos neste trabalho, abrimos a possibilidade de novas indagações que se dediquem a apontar as relações entre os seguintes fatos do nosso cotidiano: Por que as professoras/os professores tem os mais baixos salários pagos entre os profissionais de nível superior? Por que a proporção de docentes mulheres em sala de aula é muito superior à de homens na atualidade? Por que a profissão docente segue ano após ano perdendo prestígio? 
Conforme observamos, na primeira metade do século XX, embora fosse mantido o prestígio da profissão, algo necessário para tirar a mulher do lar que ela deveria governar, não foram preservados os mesmos níveis de salários ofertados aos homens, posto que se acreditava que uma mulher não deveria ser arrimo de família. Dessa maneira, a relação de poder dentro das casas conservadoras de famílias cariocas se repetia nas escolas, pois, além de remunerações mais baixas, dificilmente as mulheres ocupavam cargos de direção nas unidades escolares.

Assim, mesmo que a renda dessas professoras não fosse adequada ao seu nível de estudo, mesmo que elas dificilmente ascendessem aos cargos de direção, na primeira metade do século anterior, o exercício da docência representou um dos poucos caminhos de entrada da mulher no mercado de trabalho brasileiro. Como mostramos, as exigências para que as mulheres exercessem tais cargos não foram as mesmas. Elas foram cobradas em verdadeiros detalhes da vida pessoal, além de aspectos estéticos que visavam constituir uma imagem de perfeição, capaz de servir de exemplo de corpo e espírito para as novas gerações.

Tal notoriedade da professora primária/normalista, portanto, foi construída por interesses oficiais em mudar o ser social do brasileiro, de forma a atender as propostas de modernização do país. Alguém capaz de operar por meio do "chão da sala de aula" uma transformação que adequou a população para a mudança do eixo econômico que saiu do agropecuário para o industrializado. Um processo, segundo observamos, que foi mediado pelo nosso passado de Estado religioso e conservador, normalmente realizado por pessoas alheias à vida das discentes, resultando no controle do espírito, no tocante às ideias e valores morais, e na normatização do corpo, definindo padrões estéticos, físicos e sociais das professoras da rede oficial de ensino da capital do Brasil.

Em tempo, e voltando para os dias atuais, cabe ressaltar o crescente conservadorismo no Brasil. Com cunho igualmente religioso, alguns movimentos tentam interferir diretamente nas liberdades femininas e no fazer docente, trazendo à chefia do Estado e ao ministério da educação pessoas com um perfil ideológico ligado às igrejas evangélicas. Cabe a nós, educadores do presente e conhecedores de nossa história, continuarmos atuantes para que um período com as características que descrevemos neste artigo fique apenas no passado. 


\section{REFERÊNCIA}

A NORMALISTA vai casar depressa: Quando um Projeto é a Grande Esperança Das Alunas Casadouras - Aliança no Dedo e Livros Debaixo do Braço. Diário Carioca, Rio de Janeiro, 10 set. 1952, p. 12.

A SITUAÇÃO das normalistas - casamento só depois de formadas. Correio da Manhã, Rio de Janeiro, 11 out. 1949, p. 16.

ANTI-CRISTÃ a proibição de casamento das normalistas. Diário da Noite, 29 de jun. de 1953, p. 3.

AS ALUNAS do Instituto se Casam às Escondidas. Diário Carioca, Rio de Janeiro, 18 set. 1952, Capa.

BONATO, Nailda Marinho da Costa. A segunda escola profissional para o sexo feminino (Rivadávia Corrêa) do Distrito Federal ou a trajetória de sua diretora - Benevenuta Ribeiro (1913-1961). Série de Estudos. Campo Grande, MS, n. 25, p. 85-102, jan./jun. 2008.

BRAGA, Rubem. Pode ser legal, mas não é moral. Diário de Notícias, 2. seção, p. 1, 6 de jan. de 1949.

BRASIL. Lei de 15 de outubro de 1827. Manda crear escolas de primeiras letras em todas as cidades, villas e logares mais populosos do Imperio. Brasília, DF: Câmara do Deputados, [1827]. Disponível em: https://www2.camara.leg.br/legin/fed/lei_sn/18241899/lei-38398-15-outubro-1827-566692-publicacaooriginal-90222-pl.html. Acessado em: 29 de jul. de 2020 .

BRASIL. Presidência da República. Decreto n 4.244, de 9 de abril de 1942. Lei Orgânica do Ensino Secundário. Brasília, DF: Presidência da República, [1942]. Disponível em: http://www.planalto.gov.br/ccivil_03/decreto-lei/1937-1946/Del4244.htm. Acessado em: 19 de jul. de 2020 .

BRASIL. Presidência da República. Decreto-lei $n^{\circ}$ 8.530, de 2 de janeiro de 1946. Lei Orgânica do Ensino Normal. Brasília, DF: Câmara do Deputados, [1946]. Disponível em: http:/www2.camara.leg.br/legin/fed/declei/1940-1949/decreto-lei-8530-2-janeiro1946-458443-publicacaooriginal-1-pe.html. Acesso em: 29 jul. 2020.

BRASIL. Presidência da República. Decreto-lei $n^{\circ}$ 9.215, de 30 de abril de 1946. Proíbe a prática ou exploração de jogos de azar em todo o território nacional. Decreto-lei $n^{\circ} 9.215$, de 30 de abril de 1946. Brasília, DF: Presidência da República, [1946]. Disponível em: http://www.planalto.gov.br/ccivil_03/decreto-lei/Del9215.htm. Acesso em: 15 jun. 2020.

CARVALHO, Marta Maria Chagas de. Molde nacional e fôrma cívica: higiene, moral e trabalho no projeto da Associação Brasileira de Educação (1924-1931). Bragança Paulista, SP: EDUSF, 1998. 
CARVALHO, Marta Maria Chagas de. Quando a história da educação é a história da disciplina e da higienização das pessoas. In: FREITAS, Marcos Cezar de (org.). História social da infância no Brasil. 6. ed. São Paulo: Cortez, 2006. p. 291-310.

CONTRA o "Marido da professora"... Diário Carioca, Rio de Janeiro, 6 jan. 1949, p. 16.

CONTRAIR matrimônio: um direito das normalistas. Diário da Noite, Rio de Janeiro, 9 out. 1959 , p. 6 .

CORSI, Francisco Luiz. Política econômica e nacionalismo no Estado Novo. In: SZMRECSÁNYI, Tamás; SUZIGAN, Wilson (org.). História econômica do Brasil Contemporâneo. São Paulo: Editora da Universidade de São Paulo, 2002. p. 3-16.

DEFENDEM as normalistas o "Direito de Casar". Diário da Noite, Rio de Janeiro, 25 jun. 1953, p. 4.

DIPLOMA ou Marido. Correio da Manhã. Rio de Janeiro, 7 jan. 1949, p. 4.

DISTRITO FEDERAL. Prefeitura Municipal. Condições exigidas para o exame de admissão. Rio de Janeiro, DF: Prefeitura Municipal, [1946]. Disponível em: https:// www.jusbrasil.com.br. Acesso em: 20 out. 2017.

DISTRITO FEDERAL. Prefeitura Municipal. Decreto $n .^{\circ} 9.529$, de 28 de dezembro de 1948. Rio de Janeiro, DF: Prefeitura Municipal, [1948]. Disponível em: www.jusbrasil. com.br. Acesso em: 8 jan. 2020.

DISTRITO FEDERAL. Prefeitura Municipal. Secretaria Geral da Educação e Cultura. Departamento de Educação Complementar. Aprovação do Hino da Escola Normal Carmela Dutra. Rio de Janeiro, DF: Prefeitura Municipal, [1949]. Disponível em: https:// www.jusbrasil.com.br. Acesso em: 20 de out. 2017.

ENLUTADA a sociedade brasileira. A Noite. Rio de Janiero, 9 out. 1947, p. 2.

GOMES, Ângela de Castro. "A escola republicana: entre luzes e sombras" In: GOMES, Ângela de Castro; PANDOLFI, Dulce Chaves; ALBERTI, Verena (org.). A República no Brasil. Rio de Janeiro: Nova Fronteira, 2002. p. 383-450.

HORTA, José Silvério Baía. O hino, o sermão e a ordem do dia: regime autoritário e a educação no Brasil (1930-1945). Campinas, SP: Editores Associados, 2012.

KUSCHNIR, Karina; CARNEIRO, Leandro Piquet. As dimensões subjetivas da política: cultura política a antropologia da política. Estudos Históricos, Rio de Janeiro, v. 13, n. 24, 1999.

LEAL, José Leal; MEDEIROS, José. As professoras do futuro-Vestida de Azul e Branco. O Cruzeiro. Rio de Janeiro, p. 24, 22 out. 1949.

LIMA, Fábio Souza. A história por trás da origem do uniforme azul e branco das normalistas do Rio de Janeiro. RevistAleph, Niterói, n. 31, p. 167-188, dez. 2018. 
LIMA, Fábio Souza. As normalistas chegam ao subúrbio - A história da Escola Normal Carmela Dutra: da criação à autonomia administrativa (1946-1953). São Paulo: AllPrint, 2016.

LIMA, Fábio. Souza. As normalistas do Rio de Janeiro - O ensino normal público carioca (1920-1970): das tensões políticas na criação das instituições à produção das diferentes identidades de suas alunas. 2017. Tese. (Doutorado em Educação) - Programa de PósGraudação em Educação, Universidade Federal do Rio de Janeiro, Rio de Janeiro, 2017.

LOURO, Guacira Lopes. Gênero e Magistério: identidade, História, representação. In: CATANI, Denice et al. Docência Memória e Gênero - Estudos sobre Formação. 4. ed. São Paulo: Escrituras, 2003. p. 77-84.

LOURO, Guacira Lopes. Mulheres na Sala de Aula. In: PRIORI, Mary Del; BASSANEZI, Carla (org.). História das Mulheres no Brasil. 10. ed, São Paulo: Contexto, 2018. p. 443-481.

LUCA, Tânia Regina. A história dos, nos e por meio dos periódicos. In: PINSKY, Carla Bassanezi (org.). Fontes Históricas. São Paulo: Contexto, 2005. p. 111-142.

MAGAlHÃES JÚNIOR, Raimundo. Proibições. Diário de Notícias, Rio de Janeiro, p. 3, 6 jan. 1949.

MAGALHÃES JÚNIOR, Raimundo. A mulher não casa quando quer, mas quando é querida. Diário de Notícias, Rio de Janeiro, p. 12, 3 jul. 1953.

NAMORO, apenas... Gazeta de Notícias. Rio de Janeiro, 6 jan. 1949, p. 3.

NORMALISTA. Intérprete: Nelson Gonçalves. Compositores: NASSER, David; LACERDA, Benedito. Interprete: Nelson Gonçalves. [S.l.]: RCA Victor, 1949a. 1 disco 78 rpm, lado A. Disponível em: http://dicionariompb.com.br/nelson-goncalves/dadosartisticos. Acesso em: 22 out. 2017.

NORMALISTA - Um grande sucesso. O Cruzeiro. Rio de Janeiro, 19 nov. 1949b, p. 40.

NORMALISTAS. Diário Carioca, Rio de Janeiro, 11 jul. 1953, p. 12.

OSTOS, Natascha Stefania Carvalho de. A questão feminina: importância estratégica das mulheres para a regulação da população brasileira (1930-1945). Cadernos Pagu, Campinas, n. 39, p. 313-343, jul./dez 2012.

PASQUINI, Adriana; TOLEDO, Cézar. Historiografia da educação: A imprensa enquanto fonte de investigação. Interfaces Cientificas, Aracaju, v. 2, n. 3, p. 257-267, jun. 2014.

PROFESSORA. Intérprete: Alcides Gerard. Compositores: LACERDA, Benedito; FARAJ, Jorge; CALDAS, Silvio (1938). Interprete: Alcides Gerard. [S.l.:s.n], 1949. 1 disco 78 rpm. Disponível em: https://dicionariompb.com.br/benedito-lacerda/dadosartisticos. Acesso em: 10 out. 2017.

SAUL, Jennifer. Tratar objetos como personas Cosificación, pornografía y la historia del vibrador. Pasajes: Revista de pensamiento contemporâneo, València, n. 16, p. 103-111, oct. 2008. 
SCHWARTZMAN, Simon; BOMENY, Helena Maria Bousquet; COSTA, Vanda Maria Ribeiro; Tempos de Capanema. 2. ed. São Paulo: Editora USP; Paz e Terra, 2000.

SCOTT, Joan Wallach. História das mulheres. In: BURKE, Peter (org.). A Escrita da História. Novas Perspectivas. São Paulo: Editora UNESP, 1992. p. 63-96.

SILVA, José Claudio Sooma; VIDAL, Diana Gonçalves; ABDALA, Rachel. Fernando de Azevedo em releituras: lutas travadas, investigações realizadas e documentos guardados. Jundiaí, SP: Paco Editorial, 2020.

TONÁCIO, Glória. O processo de criação do curso normal superior no Instituto Superior de Educação do Rio de Janeiro e a sua adequação em curso de pedagogia: a tradição como farsa. Tese. (Doutorado em Educação) - Programa de Pós-Graudação em Educação, Universidade Federal do Rio de Janeiro, Rio de Janeiro, 2011.

VICENTINI, Paula. Dia do professor - 15 de outubro (1933). In: BITTENCOURT, Circe. Dicionário de datas da História do Brasil. São Paulo: Contexto, 2007. p. 245-248.

VICENTINI, Paula; LUGLI, Rosário. História da profissão docente no Brasil: representações em disputa. São Paulo: Cortez, 2009.

VIDAL, Diana; CARVALHO, Marília Pinto de. Mulheres e magistério primário: tensões, ambigüidades e deslocamentos. In: Brasil 500 anos: tópicas em história da educação, 2001.

VIDAL, Diana; FARIA FILHO, Luciano. Reescrevendo a história do ensino primário: o centenário da lei de 1827 e as reformas Francisco Campos e Fernando de Azevedo. Educação e Pesquisa, São Paulo, v. 28, n. 1, p. 31-50, jan./jun. 2002.

XAVIER, Libania Nacif. Para além do campo educacional: um estudo sobre o Manifesto dos Pioneiros da Educação Nova (1932). Bragança Paulista, SP: EDUSF, 2002.

XAVIER, Libânia Nacif; FREIRE, Américo. Educação e política na reforma da instrução pública do Distrito Federal (1927-1930). In: CONGRESSO BRASILEIRO DE HISTÓRIA DA EDUCAÇÃO, 2., 2002, Natal. Anais[...]. Natal: SBHE, 2002.

Texto recebido em 04/08/2020.

Texto aprovado em $27 / 01 / 2021$. 